\title{
EAl Endorsed Transactions

\section{Evaluation of different signal propagation models for a mixed indoor-outdoor scenario using empirical data}

\author{
Oleksandr Artemenkoํ, Alina Rubina ${ }^{1, *}$, Adarsh Harishchandra Nayak ${ }^{1}$, Sanjeeth Baptist \\ Menezes ${ }^{1}$, Andreas Mitschele-Thiel ${ }^{1}$ \\ ${ }^{1}$ Integrated Communication Systems Group, The Department of Computer Science \& Automation, Technische \\ Universität Ilmenau, 98693 Ilmenau, Germany
}

\section{Abstract}

In this paper, we are choosing a suitable indoor-outdoor propagation model out of the existing models by considering path loss and distance as parameters. A path loss is calculated empirically by placing emitter nodes inside a building. A receiver placed outdoors is represented by a Quadrocopter (QC) that receives beacon messages from indoor nodes. As per our analysis, the International Telecommunication Union (ITU) model, Stanford University Interim (SUI) model, COST-231 Hata model, Green-Obaidat model, Free Space model, Log-Distance Path Loss model and Electronic Communication Committee 33 (ECC-33) models are chosen and evaluated using empirical data collected in a real environment. The aim is to determine if the analytically chosen models fit our scenario by estimating the minimal standard deviation from the empirical data.

Received on 30 September 2015; accepted on 23 December 2015; published on 20 June 2016

Keywords: Path loss, Signal propagation models, Signal strength, Experiment

Copyright (C) 2016 Oleksandr Artemenko et al., licensed to EAI. This is an open access article distributed under the terms of the Creative Commons Attribution license (http://creativecommons.org/licenses/by/3.0/), which permits unlimited use, distribution and reproduction in any medium so long as the original work is properly cited.

doi:10.4108/eai.20-6-2016.151519

\section{Introduction}

Network planning is quite important in outdoor and indoor scenarios and the tools that are developed are to help operators to optimize their networks. These tools help in determining the best parameters like the position of an emitter node, the transmit power, and the suitable transmission channel. For these parameters to work efficiently in the chosen environment, it is also important to choose the best suited signal propagation model [1]. The propagation mechanisms are examined to help the development of propagation prediction models and to enhance the understanding of electromagnetic wave propagation phenomena involved when dealing with radio transmission in mobile and personal communication environments.

Evidently, the radio propagation phenomena are by themselves not new and do not depend on the considered environment. However, considering all the existing radio propagation phenomena, the most important one must be identified and investigated to improve the modeling of the mobile radio communication channel

${ }^{*}$ Corresponding authors. Email: alina.rubina@tu-ilmenau.de or of the prediction of radio coverage and signal quality in radio communication systems. The most important radio propagation phenomena depend on the environment and differ whether we consider a flat terrain, or houses in a suburban area, or buildings in the city center. Propagation models are efficient only when the most dominant phenomena are taken into account and in how much detail they need to be considered will also differ whether we are interested in modeling the average signal strength, or the path loss, or the power density, or any other signal characteristics.

The propagation environment causes difficulties in the investigation of the wireless signal propagation. Here, the most important aspects are as follows: (i) the distance between a base station and a receiver ranging from several meters to several kilometers, (ii) walls inside the building have sizes ranging from very small to very large in comparison to the signal wavelength and affect the propagation of the radio waves, (iii) the details of the signal propagation environment are usually not known [1]. 
In this work, the considered indoor-outdoor scenario implies communication among a quadrocopter (QC) which flies around the building and wireless nodes located inside. Since a suitable propagation model is important to work in a mixed indoor-outdoor environment we select a few of the existing signal propagation models by considering the parameters for our scenario. The literature study suggests models which work in either the indoor or the outdoor environment. By comparing other existing models, we propose to provide a model which is nearer in approximation in terms of the minimum root mean squared error (RMSE) in comparison to the log-distance path loss model, in the frequency range of $2400 \mathrm{MHz}$ and applicable in a mixed indoor-outdoor scenario. The latter considers that an emitter and a receiver are separated by one or multiple walls.

This paper provides a qualitative extension of our work in [21] which presented an adaptation of several signal attenuation models to the empirical data collected in an experimental setup. With the purpose of generalization of the obtained results, this work presents an analysis of data obtained in two experimental setups representing two different venues. Furthermore, this work extends the list of benchmark models, used in the comparison part of the paper, by the ITU model which is frequently used in the up-todate simulators [22]. The remainder of this paper is organized as follows. In Section II, we briefly describe the criteria to select the signal propagation models for our scenario and provide detailed explanation of our analytically chosen models. In Section III, we present the evaluation scenario. Section IV gives the analysis of our results. In Section V, the conclusions are drawn.

\section{State of the art}

Path loss or path attenuation is the reduction in power density of an electromagnetic wave as it propagates through space [14]. The signal propagation models are designed keeping in mind the path attenuation factor, base station antenna height, mobile station antenna height, distance and operating frequency. Several other factors also contribute to the design of a signal propagation model. For example, such models can help to find the best position of an emitter, the optimal radiated power and the best propagation channel. An overview of the existing and the most well-known signal propagation models is provided in Table 1. Next, we highlight the models selected for further evaluation.

The following models are chosen as they fall in the frequency range of approximately $2400 \mathrm{MHz}$ and the characteristics of these models are in accordance with our indoor-outdoor scenario.

Wall Attenuation Model. In order to predict the received signal strength between an emitter and a receiver, we employ the wall attenuation model [19]. In this model, the received power $P_{r}(d)$ (in $\mathrm{dBm}$ ) at a distance $d$ (in meters) from the transmitter is given by:

$$
P_{r}(d)=\bar{P}_{r}(d)+X_{\sigma}=P_{r 0}-10 \gamma \log _{10} d+X_{\sigma},
$$

where $P_{r 0}$ is the signal strength one meter from the transmitter, $\gamma$ is the path loss exponent and $X_{\sigma}$ represents a Gaussian random variable with zero mean and a standard deviation of $\sigma \mathrm{dBm}$ [8]. In the equation above, $\bar{P}_{r}(d)$ represents the mean (expected) signal strength $d$ meters from the transmitter, while $P_{r}(d)$ denotes a random outcome. This model takes into account the different obstacles present in multiple transmitter-receiver paths with the same separation. This phenomenon is referred to as the log-normal shadowing. For example, Seidel et al. report the results of modeling two office buildings at $914 \mathrm{MHz}$, with the best fits $(\gamma, \sigma)$ corresponding to $(3.27,11.2)$ and $(3.25,5.2)$ for single-floor measurements [13]. Other installations that have also been shown to follow this model can be found in $[8,11,12]$. This equation can also be extended with a wall attenuation factor $W$ :

$$
P_{r}(d)=P_{r 0}-10 \gamma \log _{10} d-\mathrm{W} \text {. }
$$

The parameter $\gamma$ defines the statistical model and is viewed as heavily dependent on the environment. Measurements in the literature have reported empirical values for $\gamma$ in the range between 1.8 (lightly obstructed environments with corridors) and 5 (multi-floored buildings), while values for $\gamma$ usually fall into the interval $(4,12) \mathrm{dBm}$ [8]. According to [19], the following parameters are representing the best fit for this model applied in a mixed indoor-outdoor scenario:

$$
P_{r 0}=-40 \mathrm{dBm}, W=4.8 \mathrm{dBm}, \gamma=3.32 \text {. }
$$

Free Space Model. The Free Space Model is also considered to be the benchmark model for our scenario. In this model, the received power is a function of the transmitted power, antenna gain and distance between a transmitter and a receiver. The basic idea is that the received power decreases as the square of the distance between the transmitter and the receiver subjected to the assumption that there is one single path between the transmitter and the receiver. The received signal power in a free space at a distance $d$ from the transmitter is [8]

$$
P_{r}(d)=P_{t} G_{t} G_{r}\left(\frac{\lambda}{4 \pi d}\right)^{2},
$$

where $P_{t}$ is the transmitted signal power, $P_{r}$ is the received signal power, $G_{t}$ is the transmitter antenna gain, $G_{r}$ is the receiver antenna gain, $\lambda$ is the wavelength. It is common to select $G_{t}=G_{r}=1$. It can 
Table 1. Existing Signal Propagation Models.

\begin{tabular}{|c|c|c|c|}
\hline Title & Signal Model & $\begin{array}{l}\text { Frequency } \\
\text { Range } \\
{[\mathrm{MHz}]}\end{array}$ & $\begin{array}{l}\text { Environ- } \\
\text { ment }\end{array}$ \\
\hline $\begin{array}{l}\text { Free Space Propa- } \\
\text { gation }[8]\end{array}$ & $L=32.44+20 \log _{10} d+20 \log _{10} f$ & NA & $\begin{array}{l}\text { Free } \\
\text { Space }\end{array}$ \\
\hline SUI [4] & $L=A+10 \gamma \log _{10}\left(\frac{d}{d_{0}}\right)+X_{f}+X_{h}+S$ & $2500-2700$ & $\begin{array}{l}\text { Indoor/ } \\
\text { Outdoor }\end{array}$ \\
\hline ECC $33[3]$ & $\begin{array}{l}L=A_{f s}+A_{b m}-G_{t}-G_{r} \\
A_{f s}=92.4+20 \log _{10} d+20 \log _{10} f \\
A_{b m}=20.41+9.83 \log _{10} d+7.894 \log _{10} f+9.56\left(\log _{10} f\right)^{2} \\
G_{t}=\log _{10} \frac{h_{b}}{200}\left[13.958+5.98 \log _{10} d\right]^{2} \\
G_{r}=\left[42.57+13.7 \log _{10} f\right]\left[\log _{10} h_{m}-0.585\right]\end{array}$ & 3500 & $\begin{array}{l}\text { Indoor/ } \\
\text { Outdoor }\end{array}$ \\
\hline $\begin{array}{l}\text { Log-distance Path } \\
\text { Loss Model [8] }\end{array}$ & $\begin{array}{l}P_{r}(d)=\bar{P}_{r}(d)+X_{\sigma} \\
P_{r}(d)=P_{r 0}-10 \gamma \log _{10} d+X_{\sigma}\end{array}$ & NA & $\begin{array}{l}\text { Indoor/ } \\
\text { Outdoor }\end{array}$ \\
\hline $\begin{array}{ll}\text { COST-231 } & \text { Hata } \\
\text { Model [6] } & \end{array}$ & $\begin{array}{l}L 50=46.3+33.9 \log _{10} f-13.82 \log _{10} h_{b}-a h_{m}+(44.9- \\
\left.6.55 \log _{10} h_{b}\right) \log _{10} d+c_{m}\end{array}$ & $500-2000$ & $\begin{array}{l}\text { Indoor/ } \\
\text { Outdoor }\end{array}$ \\
\hline $\begin{array}{l}\text { Ericsson-9999 } \\
\text { Model [10] }\end{array}$ & $\begin{array}{l}P L_{U}=a_{0}+a_{1} \log _{10} d+a_{2} \log _{10} h_{b}+a_{3} \log _{10} h_{b} \log _{10} d- \\
3.2\left(\log _{10}\left(11.75 h_{r}\right)^{2}\right)+g(f) \\
g(f)=44.49 \log _{10} f-4.78\left(\log _{10} f\right)^{2}\end{array}$ & 3500 & $\begin{array}{l}\text { Indoor/ } \\
\text { Outdoor }\end{array}$ \\
\hline Hata Model [14] & $\begin{array}{l}L 50(\text { urban })=69.55+26.16 \log _{10} f_{c}-13.82 \log _{10} h_{t}-a\left(h_{r}\right)+ \\
\left(44.9-6.55 \log _{10} h_{t}\right) \log _{10} d\end{array}$ & $150-1800$ & $\begin{array}{l}\text { Indoor/ } \\
\text { Outdoor }\end{array}$ \\
\hline $\begin{array}{l}\text { Okumura } \\
\text { Model [7] }\end{array}$ & $L 50=L_{f}+A m u(f, d)-G\left(H_{t}\right)-G\left(H_{r}\right)-G_{\text {area }}$ & $150-1920$ & $\begin{array}{l}\text { Indoor/ } \\
\text { Outdoor }\end{array}$ \\
\hline $\begin{array}{lr}\text { Walfisch } & \text { and } \\
\text { Bertoni Model [15] }\end{array}$ & $S=L 0 Q^{2} L_{r t s}$ & $800-2000$ & $\begin{array}{l}\text { Indoor/ } \\
\text { Outdoor }\end{array}$ \\
\hline $\begin{array}{l}\text { Walfisch and } \\
\text { Ikegami Model [16] }\end{array}$ & $L_{b}=L 0+L_{r t s}+L m s d$ & $800-2000$ & $\begin{array}{l}\text { Indoor/ } \\
\text { Outdoor }\end{array}$ \\
\hline $\begin{array}{ll}\text { Clutter } & \text { Factor } \\
\text { Model [16] } & \end{array}$ & $L=40 \log D-20 \log H_{m}-20 \log H_{b}$ & $30-88$ & $\begin{array}{l}\text { Indoor/ } \\
\text { Outdoor }\end{array}$ \\
\hline $\begin{array}{ll}\text { Okumura } & \text { Hata } \\
\text { Model [17] }\end{array}$ & $L=A+B \log D-E, L=A+B \log D-C$ & $150-1500$ & $\begin{array}{l}\text { Indoor/ } \\
\text { Outdoor }\end{array}$ \\
\hline $\begin{array}{l}\text { Obaidat-Green } \\
\text { model [18] }\end{array}$ & $L_{f s}=40 \log _{10} d+20 \log _{10} f-20 \log _{10} h_{t} h_{r}$ & 2400 & Outdoor \\
\hline ITU [20] & $L=20 \log _{10} f+N \log _{10} d-L_{f}(n)-28$ & $900-5200$ & Indoor \\
\hline
\end{tabular}

be expressed in $\mathrm{dBm}$ as:

$$
L=32.44+20 \log _{10} d+20 \log _{10} f[d B m] .
$$

Stanford University Interim (SUI). The IEEE 802.16 Broadband Wireless Access working group proposed the standards for the frequency band below $11 \mathrm{GHz}$ containing the channel model developed by Stanford University, namely the SUI model. The correction parameters are allowed to extend this model up to
3.5 GHz band. In USA, this model is defined for the Multipoint Microwave Distribution System (MMDS) for the frequency band from $2.5 \mathrm{GHz}$ to $2.7 \mathrm{GHz}$ [3].

The base station antenna height of the SUI model can be used from $10 \mathrm{~m}$ to $80 \mathrm{~m}$. The receiver antenna height is from $2 \mathrm{~m}$ to $10 \mathrm{~m}$. The cell radius is from $0.1 \mathrm{~km}$ to $8 \mathrm{~km}$. The SUI model describes three types of terrain: A, B and C. There is no declaration about any particular environment. Terrain A can be used for hilly areas with moderate or very dense vegetation. 
Table 2. Weather and experiment setup.

\begin{tabular}{|l|l|}
\hline Parameter & Value/Name \\
\hline \hline Air temperature & $7^{\circ} \mathrm{C}$ \\
\hline Humidity & $75, \%$ \\
\hline Speed of wind & $5, \mathrm{~m} / \mathrm{s}$ \\
\hline Air pressure & $1008, \mathrm{mb}$ \\
\hline \hline Building size data & $30 \times 20 \mathrm{~m}^{2}$ \\
\hline Number of nodes & 11 \\
\hline $\begin{array}{l}\text { Measured } \\
\text { sequences }\end{array}$ & $\mathrm{RSS}$ \\
\hline Measured parameter &
\end{tabular}

Table 3. Parameters for different terrains (SUI model).

\begin{tabular}{|l|l|l|l|}
\hline Constants & Terrain A & Terrain B & Terrain C \\
\hline $\mathrm{a}$ & 4.6 & 4 & 3.6 \\
\hline $\mathrm{b}$ & 0.0075 & 0.0065 & 0.005 \\
\hline $\mathrm{c}$ & 12.6 & 17.1 & 20 \\
\hline
\end{tabular}

This terrain presents the highest path loss. Terrain B is characterized with either mostly flat terrains with moderate to heavy tree densities or hilly terrains with light tree densities. This is the intermediate path loss scheme. Terrain $\mathrm{C}$ is associated with minimum path loss and applies to flat terrains with light tree densities. The basic path loss expression of the SUI model with correction factors is presented as $[4,5]$ :

$$
L=A+10 \gamma \log _{10} \frac{d}{d 0}+X_{f}+X_{h}+S \text { for } d>d_{0},
$$

where $d$ is the distance between the emitter and the receiver in meters, $d_{0}=100 \mathrm{~m} ; \lambda$ is the wavelength in meters; $X_{f}$ is the correction for frequency above $2 \mathrm{GHz} ; X_{h}$ is the correction for the receiver antenna height, $S$ is the correction for shadowing in the range between 8.2 and 10.6 in $\mathrm{dBm}, \gamma$ is the path loss exponent [4]. The parameter $A$ and $\gamma$ are defined as:

$$
\begin{aligned}
& A=20 \log _{10} \frac{4 \pi d 0}{\lambda}, \\
& \gamma=a-b h_{b}+\frac{c}{h_{b}},
\end{aligned}
$$

where the parameter $h_{b}$ is the base station antenna height in the range between $10 \mathrm{~m}$ and $80 \mathrm{~m}$. The constants $\mathrm{a}, \mathrm{b}$, and $\mathrm{c}$ depend upon the type of terrain and are given in Table 3. As a result, the value of parameter $\gamma=2$ corresponds to the free space propagation in an urban area, $3<\gamma<5$ to an urban non-line-of-sight environment, and $\gamma>5$ to an indoor propagation.

The frequency correction factor $X_{f}$ and the correction for the receiver antenna height $X_{h}$ are defined as follows:

$$
\begin{aligned}
& X_{f}=6.0 \log _{10} \frac{f}{2000} \\
& X_{h}=10.8 \log _{10} \frac{h_{r}}{2000}, \text { for terrain types A and B } \\
& X_{h}=-20.0 \log _{10} \frac{h_{r}}{2000}, \text { for terrain type C, }
\end{aligned}
$$

where $f$ is the operating frequency in $\mathrm{MHz}$, and $h_{r}$ is the receiver antenna height in meters. For the above correction factors this model is extensively used for the path loss prediction of all three terrain types in rural, urban and suburban environments.

Electronic Communication Committee 33 (ECC-33) Model. The ECC 33 path loss model, which is developed by Electronic Communication Committee (ECC), is extrapolated from the original measurements by Okumura [7]. The model is defined as [3]:

$$
P L(d B m)=A_{f s}+A_{b m}-G_{t}-G_{r},
$$

where $A_{f s}$ is the free space attenuation, $A_{b m}$ is the basic median path loss, $G_{t}$ is the base station height gain factor and $G_{t}$ is the receiving antenna height gain factor. These parameters are individually defined as:

$$
\begin{aligned}
A_{f s} & =92.4+20 \log _{10} d+20 \log _{10} f \\
A_{b m} & =20.41+9.83 \log _{10} d+7.894 \log _{10} f+ \\
9.56\left[\log _{10} f\right]^{2} & \\
G_{t} & =\log _{10} \frac{h_{b}}{200}\left[13.98+5.8\left(\log _{10} d\right)^{2}\right] \\
G_{r} & =\left[42.57+13.7 \log _{10} f\right]\left[\log _{10} h_{m}-0.585\right],
\end{aligned}
$$

where $d$ is the distance between the base station and the mobile in kilometers, $h_{b}$ is the base station antenna height and $h_{m}$ is the mobile antenna height in meters.

COST-231 Hata Model. A model that is widely used for predicting path loss in mobile wireless systems is the COST-231 Hata model [6]. It was devised as an extension to the Hata-Okumura model [7]. The COST-231 Hata model is designed to be used in the frequency band from $500 \mathrm{MHz}$ to $2000 \mathrm{MHz}$. It also contains corrections for urban, suburban and rural (flat) environments. Although its frequency range is outside of the one used in our measurements, its simplicity and the flexibility have motivated many researchers to widely use it for the path loss prediction in frequencies above $2000 \mathrm{MHz}$. The basic equation for the path loss in $\mathrm{dBm}$ can be expressed as [8]:

$$
L=46.3+33.9 \log _{10} f-13.82 \log _{10} h_{b}-a h_{m}+(44.9-
$$
$\left.6.55 \log _{10}\left(h_{b}\right)\right) \log _{10} d+c_{m}$, 


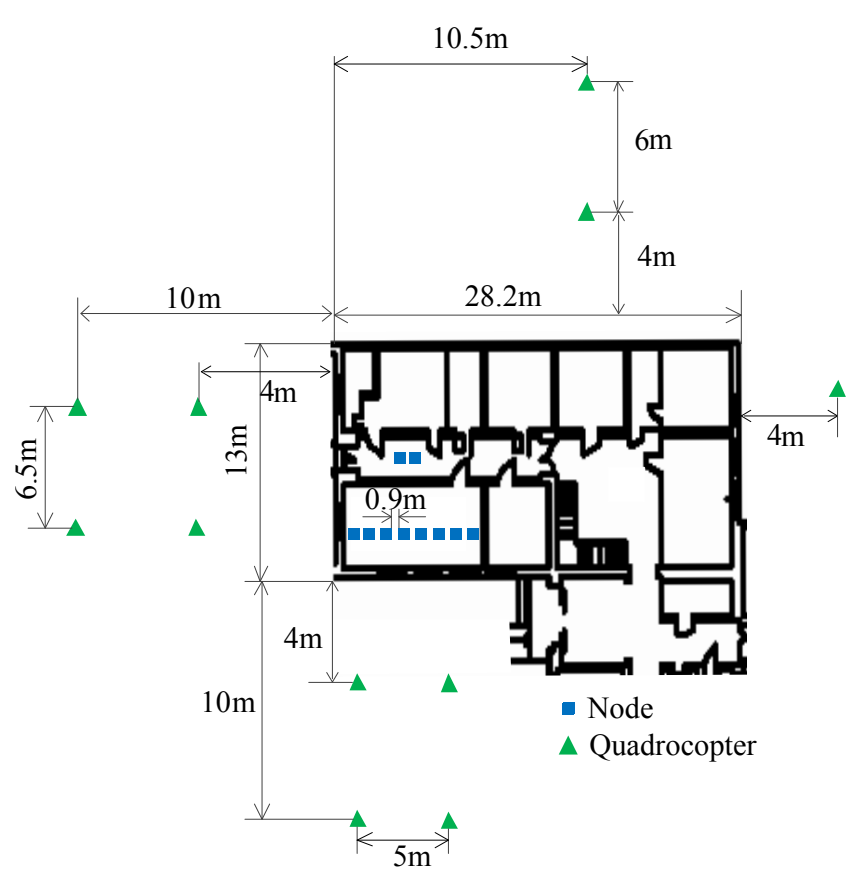

Figure 1. Floorplan of the Helmholtzbau building. The locations of the QC and the nodes are marked accordingly.

where $f$ is the frequency in $\mathrm{MHz}, d$ is the distance between antennas in kilometers, and $h_{b}$ is the transmitter antenna height above ground level in meters. The parameter $c_{m}$ is defined as $0 \mathrm{dBm}$ for suburban or open environments and $3 \mathrm{dBm}$ for urban environments. The parameter $a h_{m}$ is defined for the urban environments as [9]:

$$
a h_{m}=3.20\left(\log _{10}\left(11.75 h_{r}\right)\right)^{2}-4.97, \text { forf }>400 \mathrm{MHz} \text {, }
$$

and for the suburban or rural (flat) environments as:

$$
a h_{m}=\left(1.1 \log _{10} f-0.7\right) h_{r}-\left(1.56 \log _{10} f-0.8\right),
$$

where $h_{r}$ is the antenna height above ground level. Observation reveals that the path loss exponent of the predictions made by the COST-231 Hata model is given by:

$$
n_{\operatorname{COST}}=\frac{\left(44.9-6.55 \log _{10}\left(h_{b}\right)\right)}{10} .
$$

Green-Obaidat Model. This model was first described by Green and Obaidat [18] in 2002. It considers the path loss accounting due to the Fresnel zone with near earth antenna height (i.e., typically between 1 and 2 meters) [18]. The proposed path loss for near ground

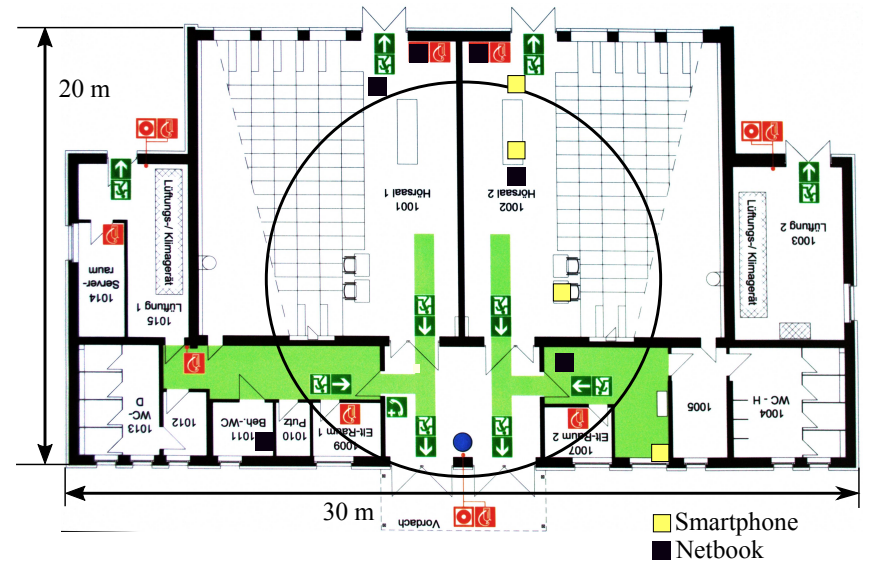

Figure 2. The floor-plan of the Leonardo Da Vinci building. Positions of the smartphones and netbooks are marked accordingly.

antennas is as follows:

$$
P_{\text {LOSS }}=40 \log _{10} d+20 \log _{10} f-20 \log _{10} h_{t} h_{r},
$$

where $f$ is the frequency in $\mathrm{GHz}, h_{t}$ and $h_{r}$ represent the antenna heights for the transmitter and the receiver correspondingly, and $d$ is the overall distance. This equation can further be simplified for $f=2.4 \mathrm{GHz}$ frequency as:

$$
P_{\text {LOSS }}=7.6+40 \log _{10} d-20 \log 10 h_{t} h_{r} .
$$

International Telecommunication Union (ITU) Model. The International Telecommunication Union (ITU) developed numerous models suitable for scenarios like outdoor, urban, indoor, micro- and macrocell propagation. However, the most suitable for our scenario is the indoor propagation model. The ITU indoor propagation model can be expressed in $\mathrm{dB}$ as follows:

$$
L=20 \log _{10} f+N \log _{10} d-L_{f}(n)-28,
$$

where $f$ is the frequency in $\mathrm{MHz}, N$ is the distance power decay index, $d$ is the distance in meters, $L_{f}(n)$ is the floor penetration loss factor and $n$ is the number of the floors between the transmitter and the receiver [20].

Next, the above models will be evaluated according to our empirical data.

\section{Evaluation}

For the evaluation of our scenario, we have considered two different buildings to introduce the diversity. Our experiments took place at the Leonardo Da Vinci and Helmholtzbau buildings on the TU Ilmenau campus. 


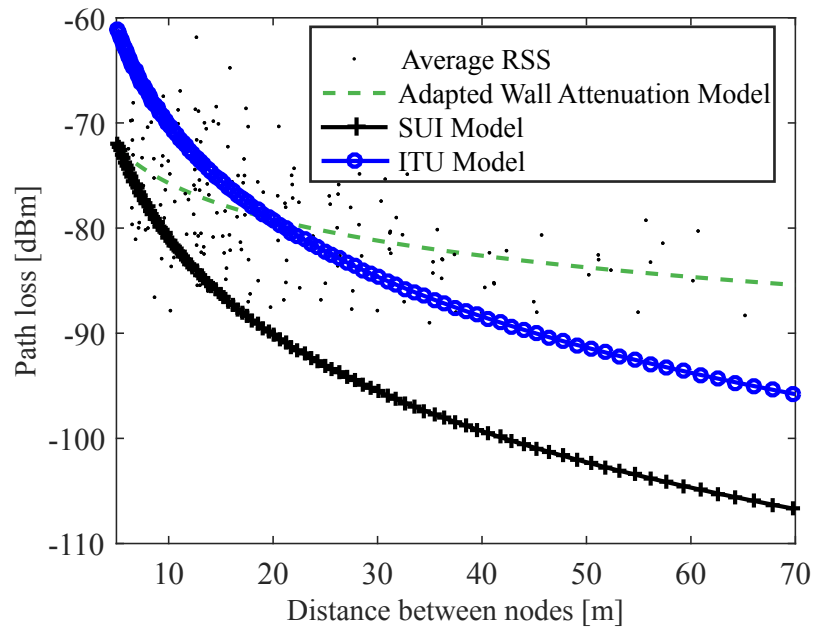

(a) Considering only outdoor measurements

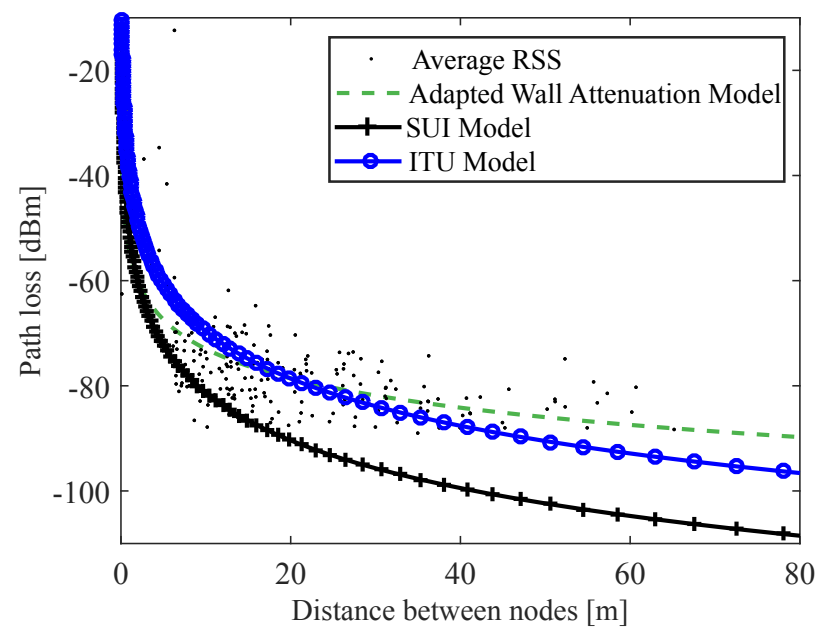

(b) Considering outdoor and indoor measurements

Figure 3. Received signal strength vs. distance.

Fig. 1 demonstrates the floor plan of the Helmholtzbau building. The positions of the nodes and QC are marked accordingly. The building plan including the placement of nodes in case of Leonardo Da Vinci building is shown in Fig. 2. The nodes in black represent the netbooks and the nodes in yellow represent the smartphones.

For our experiments, we used two types of devices: five ASUS Eee PC Seashell series netbooks and five smartphones Samsung Galaxy S. In case of Helmholtzbau, received signal strength (RSS) readings were collected using a Quadrocopter (QC) positioned at discrete locations outside and inside the building at roughly every $6 \mathrm{~m}$. At each location, we gathered approximately 120 beacons, a procedure which took us about 2 minutes per location. Our QC was placed in 12 different locations around the building. As a result, the QC and nodes were separated by one to four different walls. In this way, we wanted to introduce diversity.

In case of Leonardo Da Vinci, outdoor measurements were taken both in the front and rear (South and North correspondingly) of the building by placing the quadrocopter at distances of 5, 10, 12, 15, 20 meters in the front, and $5,10,16,20,25,30,35,40,50,55$ meters in the rear. Since some models require reference measurements at distance $d=1 \mathrm{~m}$, these measurements have been carried out indoors (the average value is $P_{r 0}=$ $37 \mathrm{dBm}$ ). For further indoor measurements, the nodes were placed equidistant at intervals of 0.9 meters. The technical specifications of the QC are given in Table 4.

Table 5 gives a description of the propagation parameters used for the evaluation of results. These parameters have been used to find the best match for every signal propagation model described above. We used the brute force method to go through all possible
Table 4. Technical parameters of quadrocopter.

\begin{tabular}{|l|l|}
\hline $\begin{array}{l}\text { Technical Characteris- } \\
\text { tic }\end{array}$ & Model or Parameter \\
\hline Processor & $600 \mathrm{MHz}$ Cortex A8 \\
\hline RAM & $256 \mathrm{MB}$ \\
\hline $\begin{array}{l}\text { Gyroscope/Acceleration } \\
\text { Sensor }\end{array}$ & MPU6050 \\
\hline Magnetic Field Sensor & HMC5883L \\
\hline GPS Receiver Pressure & UBLOX6 \\
\hline $\begin{array}{l}\text { Barometric } \\
\text { Sensor }\end{array}$ & MaxSonar I2CXL \\
\hline Ultrasonic Sensor & Gentoo Linux \\
\hline Operating System & $\begin{array}{l}\text { PenguPilot hit- } \\
\text { hub.com/PenguPilot) }\end{array}$ \\
\hline $\begin{array}{l}\text { Flight and Measurement } \\
\text { Software }\end{array}$
\end{tabular}

constellations of the values for the path loss exponent $\gamma$ and the intercept (intercept has been applied for the log-distance and wall attenuation models only). For every combination of $\gamma$ and intercept, an RMSE value has been calculated as an indication of correspondence to our empirical data. The smaller an RMSE value is, the more precisely a model fits to our scenario.

\section{Evaluation results}

Using the data obtained in our setup, we evaluated the path loss in $\mathrm{dBm}$ with respect to the distance between the emitter nodes and the QC. In Fig. 3(a), we plot the average signal strength measurements for different distance values using outdoor measurements 


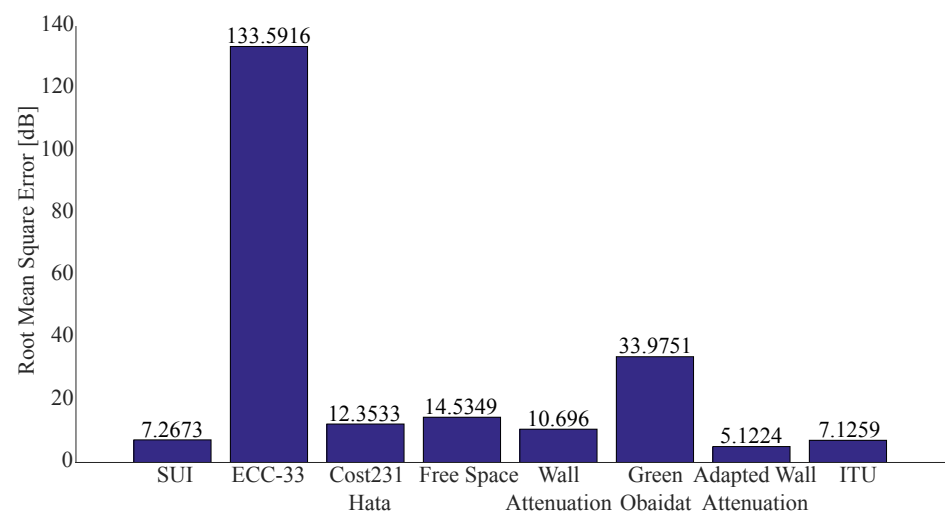

(a) Considering outdoor measurements only

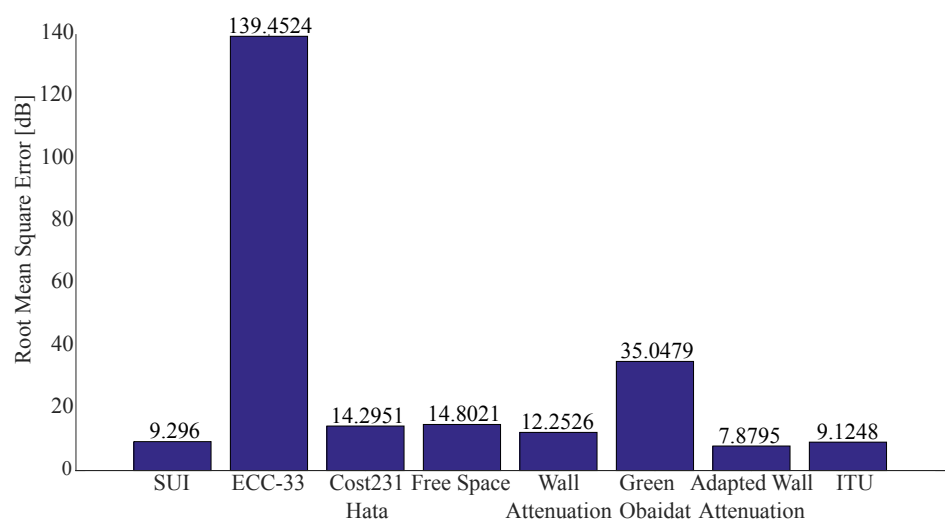

(b) Considering outdoor and indoor measurements

Figure 4. Comparison of chosen models.

Table 5. Propagation parameters for the evaluation.

\begin{tabular}{|l|l|}
\hline Parameters & Values \\
\hline Frequency & $2.4 \mathrm{GHz}$ \\
\hline Distance $d_{0}$ & $1 \mathrm{~m}$ \\
\hline Receiver antenna height & $0.15 \mathrm{~m}$ \\
\hline Wavelength $\lambda$ & $0.12 \mathrm{~m}$ \\
\hline $\begin{array}{l}\text { Transmitter antenna } \\
\text { height }\end{array}$ & $1.2 \mathrm{~m}$ \\
\hline Path loss exponent $\gamma$ & {$[1,5]$} \\
\hline Intercept & {$[0,100] \mathrm{dBm}$} \\
\hline $\begin{array}{l}\text { Floor penetration loss } \\
\text { factor } L_{f}(n)\end{array}$ & 0 \\
\hline
\end{tabular}

only. Whereas, Fig. 3(b) incorporates both indoor and outdoor measurements.

Both Fig. 3(a) and Fig. 3(b) show three curves: the adapted wall attenuation model, the SUI model and the ITU model. According to our evaluation, these models fit the best to our empirical data. It is obvious in both figures that the SUI model, presenting the third best result in this work, deviates significantly from the cloud of measurements. Two other curves behave similar and only the RMSE can identify the winner.

According to the RMSE, the adapted wall attenuation model provides the best result using the path loss exponent $\gamma=1.8574$ and the sum of the transmitted power and wall attenuation factor at $54.4117 \mathrm{dBm}$. The chosen RMSE for all models is shown in Fig. 4(a) which represents the RMSE for the measurements taken with the QC being outside of the building, whereas Fig. 4(b) represents the RMSE for all measurements. In both figures, the adapted wall attenuation model outperforms its opponents presenting RMSE values 5.1 and 7.8 considering outdoor measurements and all measurements correspondingly. It is worth noticing that the ITU model with RMSE values 7.1 and 9.1 correspondingly presents the second best result following the winner very closely. Considering the high heterogeneity of data applied for the calculation of the RMSE using measurements from both indoor and outdoor environments, we can explain the enormous degradation and almost doubled value of the RMSE compared to the results achieved with outdoor measurements only. 


\section{Conclusion}

As per the analysis of the chosen models, we obtained the minimum root mean squared error (RMSE) using the adapted wall attenuation model. The ITU model, the SUI model, the Free Space Model and the COST-231 Hata model provide the next best possible choice with respect to the minimum error. Hence for the chosen set of parameters and for the chosen mixed indooroutdoor environment, the adapted wall attenuation model provides a closer approximation of the RMSE in comparison to other models.

Comparing the obtained set of values for the adapted wall attenuation model $\left(P_{r 0}=37 \mathrm{dBm}, W=\right.$ $17.4 \mathrm{dBm}, \gamma=1.9)$ with the one of the original model from [19] $\left(P_{r 0}=40 \mathrm{dBm}, W=4.8 \mathrm{dBm}, \gamma=3.32\right)$, we can conclude the following:

- The obtained RMSE for the model with the adjusted parameters is significantly better than the original one (the corresponding ratio is 2.2 for outdoor measurements).

- The ITU model which is suited for indoor signal propagation has shown the second best fit to the obtained data.

- Similar environmental conditions do not guarantee similar behavior of the signal propagation.

- A calibration of parameters can improve the accuracy of the model significantly. However, such a calibration represents an overhead and needs to be periodically repeated for the same area. This is partially due to the fact that the environmental conditions like temperature, light, open and closed doors and windows of the building can have a considerable impact on the resulting signal propagation.

\section{References}

[1] D. J. Cichon and T. Kuerner, "Propagation Prediction Models", Prentice Hall, 2002.

[2] S. R. Saunders and A. A. N-Zavala, "Antennas and propagation for wireless communication systems", 2nd Edition, John Wiley and Sons, Ltd, 2007.

[3] V.S. Abhayawardhana, I.J. Wassell, D. Crosby, M.P. Sellars, M.G. Brown, "Comparison of empirical propagation path loss models for fixed wireless access systems", Vehicular Technology Conference, 2005. IEEE Date: 30 May-1 June 2005 Volume: 1, On page(s): 73-77 Vol. 1.

[4] V. Erceg, K. V. S. Hari, et al., "Channel models for fixed wireless applications", tech. rep., IEEE 802.16 Broadband wireless access working group, Jan-2001.

[5] V. Erceg, L. J. Greenstein, et al., "An empirically based path loss model for wireless channels in suburban environments", IEEE Journal on Selected Areas of Communications, vol. 17, pp. 1205âĂŞ1211, July 1999.
[6] COST Action 231, "Digital mobile radio towards future generation systems", final report, tech. rep., European Communities, EUR 18957, 1999.

[7] T. Okumura, E. Ohmori, and K. Fukuda, "Field strength and its variability in VHF and UHF land mobile service", Review Electrical Communication Laboratory, Vol. 16, No. 9-10, pp. 825-873, Sept.-Oct. 1968.

[8] T. S. Rappaport, "Wireless communication - Principles and practice", 2nd Edition, Prentice Hall, 2001.

[9] H. R. Anderson, "Fixed Broadband Wireless System Design." John Wiley and Co., 2003.

[10] J. Milanovic, Rimac-Drlje S., Bejuk K., "Comparison of propagation model accuracy for WiMAX on 3.5GHz", 14th IEEE International conference on electronic circuits and systems, Morocco, pp. 111-114. 2007.

[11] H. Hashemi., "The Indoor Radio Propagation Channel", Proceedings of IEEE, 81(7):943-968, July 1993.

[12] D. Molkdar., "Review on Radio Propagation into and within Buildings", IEEE Proceedings-H, 138(1):61-73, Feb. 1991.

[13] S. Y. Seidel and T. S. Rappaport., "914 MHz Path Loss Prediction Models for Indoor Wireless Communications in Multifloored Buildings", IEEE Transactions on Antennas and Propagation, 40(2):207-217, Feb. 1992.

[14] M. Hata, "Empirical Formula for Propagation Loss in Land Mobile radio Service", IEEE Transactions on Vehicular Technology, 1980.

[15] J. Walfisch and H.L. Bertoni, "A Theoretical Model of UHF Propagation in Urban Environments", IEEE Transactions on Antennas and Propagation, 1988.

[16] K. Low, "Comparison of Urban Propagation Models with CW Measurements", IEEE Vehicular Technology Society 42nd VTS Conference. Frontiers of Technology. pp 936942.

[17] R. Leppaenen, J. Laehteenmaeki, S. Tallqvist, "Radiowave propagation at 900 and $1800 \mathrm{MHz}$ bands in wooded environments," COST 231 TD(92)112, Helsinki, 1992.

[18] Green, D. B.; Obaidat, A. S., "An accurate line of sight propagation performance model for ad-hoc 802.11 wireless LAN (WLAN) devices" Communications, 2002. ICC 2002. IEEE International Conference on, vol.5, 2002.

[19] D. B. Faria, "Modeling Signal Attenuation in IEEE 802.11 Wireless LANs - Vol. 1", Technical Report TR-KP06-0118, Kiwi Project, Stanford University, Jan. 2006.

[20] Chrysikos, T.; Georgopoulos, G. \& Kotsopoulos S., "Sitespecific validation of ITU indoor path loss model at 2.4 GHz", in WOWMOM, IEEE, pp. 1-6, 2009.

[21] O. Artemenko, A. Harishchandra Nayak, S. Baptist Menezes, A. Mitschele-Thiel, "Evaluation of Different Signal Propagation Models for a Mixed Indoor-Outdoor Scenario Using Empirical Data", 7th International Conference on Ad Hoc Networks (ADHOCNETS'15), San Remo, Italy, September 2015.

[22] Kamarudin, L.M.; Ahmad, R.B.; Ong, B.L.; Malek, F.; Zakaria, A.; Arif, M.A.M., "Review and Modeling of Vegetation Propagation Model for Wireless Sensor Networks Using Omnet++," in Network Applications Protocols and Services (NETAPPS), 2010 Second International Conference on , vol., no., pp.78-83, 22-23 Sept. 2010. 